\title{
Urban Nature: Does Green Infrastructure Relate to the Cultural and Creative Vitality of European Cities?
}

\author{
Vishal Kumar 1,2,* and Aude Vuilliomenet ${ }^{1, *}$ \\ 1 The Bartlett, Centre for Advanced Spatial Analysis, University College London, London WC1E 6BT, UK \\ 2 Cultureincities Ltd., 71-75 Shelton Street, London WC2H 9JQ, UK \\ * Correspondence: v.kumar.17@ucl.ac.uk (V.K.); aude.vuilli@gmail.com (A.V.)
}

Citation: Kumar, V.; Vuilliomenet, A. Urban Nature: Does Green

Infrastructure Relate to the Cultural and Creative Vitality of European Cities?. Sustainability 2021, 13, 8052. https://doi.org/10.3390/su13148052

Academic Editors: Valentina

Montalto, Michaela Saisana and Pier Luigi Sacco

Received: 26 April 2021

Accepted: 29 June 2021

Published: 19 July 2021

Publisher's Note: MDPI stays neutral with regard to jurisdictional claims in published maps and institutional affiliations.

Copyright: (C) 2021 by the authors Licensee MDPI, Basel, Switzerland. This article is an open access article distributed under the terms and conditions of the Creative Commons Attribution (CC BY) license (https:/ / creativecommons.org/licenses/by/ $4.0 /)$.

\begin{abstract}
The COVID-19 pandemic severely upended cultural and creative production, consumption, and interactions in cities. Open green spaces, parks, forests, and gardens—green infrastructure-were instead utilized by citizens as a substitute for stimulating social interactions, sustainable tourism, and green growth. (1) The purpose of this research is to understand whether the availability of green infrastructure relates to the Cultural and Creative Cities Monitor (CCCM) benchmarking project developed by the Joint Research Centre of the European Commission performance. Does new evidence suggest revising the CCCM conceptual framework and related urban policies, especially in relation to the EU Green Deal? (2) Data from OpenStreetMap was used to count the amount of green infrastructure in 184 European Cities covered by the CCM and was then correlated with the sub-indices of the CCCM. (3) We found a moderately positive correlation of green infrastructure with the cultural vibrancy of a city and a weak positive correlation with the enabling environment of a city. (4) In light of the COVID-19 pandemic, the EU Green Deal and several other policy initiatives aimed at urban greening, we recommend that the CCCM include an Urban Nature sub-index as one of the performance indicators of the CCCM. An Urban Nature sub-index will broaden the goal of the CCCM by providing policymakers with a better understanding of actions and strategies to allow culture to contribute to social inclusion and green growth strategies in cities.
\end{abstract}

Keywords: green infrastructure; urban nature; culture in cities; cultural vibrancy; creative economy; enabling environment; Cultural and Creative Cities Monitor; OpenStreetMap; city

\section{Introduction}

Culture is important for a city's vibrancy, economy and enabling environment. However, the COVID-19 pandemic has severely upended cultural and creative production, consumption, and interactions in cities. During the pandemic, however, one element of cities gained much attention as a substitute for stimulating social interactions and sustainable growth: green infrastructure.

People living in and around metropolitan areas have been forced to use open green spaces to make the most of socially distanced interactions for their wellbeing and fitness. For example, Venter et al. [1] estimated that there was a $291 \%$ increase in outdoor recreational activity in Oslo, Norway during the pandemic, especially amongst pedestrians in city parks, peri-urban forests, as well as protected areas, highlighting the importance of access to green open spaces for recreational activity. Moreover, using mobility data from Google, Day [2] found that over the period of 15 February to 7 June 2020, the visitation to parks in England was around 37\% over the baseline level. While the first period of strict lockdown forced citizens to stay home, trips taken by cars to green spaces decreased $47 \%$, yet people engaged substantially more with walking as trips taken to greenspaces by foot rose by $34 \%$. These findings are supported and explained by other researchers. Kleinschroth and Kowarik [3] found that due to the COVID-19 restrictions and the constraints of various governments' "stay-at-home" policies, people's interest in "going for 
walks" and in engaging in short-distance outdoor activities increased. This is supported by Ugolini et al. [4], who observed an increase in people walking to nearby small urban gardens in Italy or spending more time on tree-lined streets in Spain.

Hanzl [5] highlighted the various interventions taken by cities and governments globally to "facilitate healthier lifestyles while preventing the spread of the virus" as people adopted work-from-home patterns and recreational and leisure centres closed. Many of the COVID-19 related social and cultural adjustments made by cities such as London, New York, Auckland, or Warsaw have been related to green infrastructure; for instance, streets in proximity to parks were closed to motor vehicles, parking lots were converted into parklets or pocket parks, and motor vehicles lanes were reallocated to pedestrians and bicyclists. These findings support the research by Herman and Drozda [6] on the importance of multifunctional spaces, especially the role of local green areas as nodes and centres of importance for the local community. Artists have also responded to social distancing measures; for example, StoDistante ('I'm keeping my distance' in Italian), completed in May 2020, an installation in Vicchio, near Florence, created by local architects Caret Studio, "addresses Tuscany's current social-distancing regulations" [7]. As mentioned by HoneyRosés et al. [8], the COVID-19 pandemic has created opportunities to "rethink urban policy and planning" and more than ever, it has highlighted the need for large and small parks that can be accessed by all citizens within walking distance from their home [4].

Cultural spaces are likely to be subject to distancing rules even after the end of lockdown period and green spaces may become crucial to maintain the cultural offer within cities in a safe and open environment. The availability of green infrastructure post-pandemic, therefore, may become a key asset for cities wishing to put culture at the core of their sustainable development strategies.

Many definitions of green infrastructure (GI) have been developed. The European Commission communication "Green Infrastructure-Enhancing Europe's Natural Capital" (EC, 2013) describes GI as a "tool for providing ecological, economic, and social benefits through natural solutions". It helps us to understand the advantages nature offers human society and to mobilize investments that sustain and enhance these benefits. Naumann et al. [9] mention that GI has a broad concept that includes natural features, such as parks, forest reserves, hedgerows, restored and intact wetlands and marine areas, as well as man-made features, such as wildlife crossing bridges and cycle paths. They point out one of the key attractions of GI: its multifunctionality-i.e., its ability to perform and provide several functions and benefits on the same spatial area. In this study, GI encompasses natural, vegetation-covered or maintained green areas and features of the urban landscape. Our research does not include blue infrastructure, i.e., GI that describes blue spaces such as aquatic ecosystems and other physical features in coastal and marine areas.

Green infrastructure offers a variety of benefits to urban dwellers that are well covered by the literature: an increase in biodiversity that supports rich assemblages of wildlife, including many rare and endangered species [10,11]; mitigation of climate change through reducing urban heat island effects [12] and water runoff [13,14]; and, the contribution to individual health and wellbeing [15] through increased physical activity [16] and decreased stress in deprived communities [17]. In particular, considerable research has examined the role of the physical environment of green spaces in facilitating social cohesion. For example, the presence of trees has greater potential to encourage the utilization of common spaces and favours positive informal social interactions between visitors [18-20]. Meanwhile, subjective environmental factors such as perceived greenness [21,22] and the perception of safety $[23,24]$ as well as nature dose such as the frequency and duration of visiting green spaces [25-27] have been found to be crucial in promoting social cohesion.

There are three major aspects of green spaces contributing to the development of social cohesion, namely, physical characteristics, perceptions of the environment, and use patterns. A robust literature has established a significant association between the presence of vegetation and various forms of social process [20,21,28-31]. The presence of trees and grass was suggested to encourage greater use of outdoor spaces, thereby increasing the 
possibility of informal social contact with others [18]. Subsequent research [19] has proved that the level of vegetation is positively associated with the use of common spaces and social ties among respondents; the study also empirically confirmed the mediating role of use in the relationship between vegetation and social ties. Other research literature has reported the impact of vegetation on different aspects of social cohesion. A living environment with more parks is strongly associated with a higher level of reported social cohesion [32].

The facilities on offer inside the green infrastructure are a prerequisite for developing quality social interactions in public spaces [33]. Research literature has provided a positive relationship between the supply of facilities and various forms of social processes. For instance, community gardens are in themselves a place where participants can build up new friendships over an interest of gardening, sharing their produce with others, spending more time gardening with their families, and meeting up with their neighbours, which all contribute to improved social ties and social support [34-36]. Moreover, the availability of benches, tables, and playground facilities in community gardens form a friendly social area wherein individuals can socialize with each other [37]. The provision of playgrounds not only increases social interactions among children but also interactions between their guardians [38]. Revealed by respondents of a focus group discussion conducted in the United Kingdom, bleak landscapes that lack facilities limit the use of parks for pleasure and opportunities for social interactions [25]. In contrast, parks with a full range of facilities serve a diverse set of users, providing opportunities for contact between people with different racial and ethnic backgrounds [39]. In sum, facilities in green spaces encourage visitations and promote social interactions among visitors. They are indispensable in promoting social cohesion in urban green environments.

However, in light of green infrastructure's role as an enabler of social interaction and sustainable green tourism during the COVID-19 pandemic, the relationship between green infrastructure and whether it contributes to a city's cultural vibrancy, creative economy and enabling environment is poorly understood. Indeed, the European Commission's Cultural and Creative Cities Monitor [40] (the CCCM) of 2019 notably does not include an indicator or metric for green infrastructure. However, social-ecological approaches that provide environmental, social, and economic benefits, referred to as nature-based solutions (NBS), have been discussed and promoted by several institutional bodies over the last five years. The European Commission first mentioned them in the final report of the Horizon 2020 [41] and recently published a handbook for practitioners to share best practices to evaluate the impact and performance of the so-called nature-based solutions [42]. The implementation of broad and wide interventions based on nature have been at the heart of the European Green Deal, which defines a new growth strategy for the EU with the commitment to tackle environmental-related challenges while ensuring innovation and economic growth [43].

Cultural and natural interventions are at the core of EU strategies and initiatives, yet it appears that further research could shed some light on how both are intrinsically linked and how their entanglement could help answer some of the EU's most pressing policy goals. The purpose of this paper is to retroactively measure the relationship between green infrastructure and the cultural vibrancy, creative economy and enabling environment of a city based on the data and indicators of the CCCM collected in 2019. It looks at the following questions: does the availability of green infrastructure relate to cultural and creative cities' performance? Does new evidence suggest revising the CCCM conceptual framework and related urban policies, especially in relation to the EU Green Deal? The study's hypothesis is that there is a positive relationship between the amount and variety of green infrastructure in a city and the availability and variety of its cultural and creative offering as well as ability to enable and encourage social interactions amongst all types of people.

Data on green infrastructure from OpenStreetMap was collected for 184 European cities and a new "green infrastructure" dimension was added to the CCCM. This paper then correlated the amount of green infrastructure in a city to its cultural vibrancy, creative econ- 
omy, and its enabling environment. Our results show that there is a positive relationship between the amount of green infrastructure in a city and its cultural vibrancy and enabling environment, but less so for its creative economy. Although it is difficult to draw causality from these preliminary studies, this research provides the basis for a future exploration into more complex spatial regression and agent-based models to determine causality and help policymakers to increase inclusiveness through green growth and tourism and improve health and wellbeing.

\section{Materials and Methods}

Our entire analysis, data and code can be found inside one Google Colaboratory notebook on our GitHub (https:/ / github.com/cultureincities/UrbanNature-CulturalCreativeCities, accessed on 24 May 2021). The following section lays out our methods in more detail.

\subsection{Cultural and Creative Cities Monitor Data}

Firstly, the CCCM's data was downloaded as an Excel spreadsheet from the Docs and Data section of the main website. In total, there are 190 cities, and the dataset is categorized based on the following criteria (Annex A):

1. Cities that have been or will be European Capitals of Culture (EcoC) up to 2019, or that have been shortlisted to become an EcoC up to 2021-98 cities;

2. UNESCO Creative Cities (including the most recent winners in 2015)—excluding overlap with the EcoC, a further 33 cities;

3. Cities hosting at least two regular international cultural festivals running until at least 2017—a further 59 cities.

The CCCM compares cities' cultural and socio-economic vitality using common measurement criteria. Each city score is calculated as a weighted average of three sub-indices: cultural vibrancy, creative economy, enabling environment. The cultural vibrancy reflects the cultural richness of a city measuring the number of cultural venues and facilities as well as its cultural attractiveness and public participation. The creative economy reports the level of employment in the creative sector and level of innovation through the number of patent applications. Finally, the enabling environment captures the openness, connectedness, and educational dynamism.

\subsection{Data Collection from OpenStreetMap}

Data on green infrastructure for the 190 cities were collected from OpenStreetMap (OSM). The OSM dataset represents physical features that are mapped on the ground as a single element with either a single tag, or a small number of tags to classify it. The tag "natural" and "landuse" was firstly queried using the OSMnx Python library to obtain all natural and land use values for each city. However, this method only returned data for 62 cities. The reason for this is because the library takes a string as input to describe the city and country-for example, "London, United Kingdom" - however, for the remaining 128 cities, there was a mismatch between this semantic and how the OSMnx Python library interpreted the string.

We needed a more reliable way to query OSM to collect data for the cities in the CCCM. To overcome this issue, we used a second library, the OSMPythonTools, a python package that provides easy access to OSM-related services, among them Nominatim API, Overpass API and OSM API. The Nominatim API was used to find the OSM areaID for each city. The areaID for a city seemed to be a more reliable input rather than a descriptive string of the city and country-i.e., "Paris, France". Using the Nominatim API, 184 cities were returned with an areaID, the Nominatim API did not give an areaID for the following cities: "San Sebastian-Donostia, Spain”, "Glasgow, UK”, “Dundee, UK", “Aarhus, Denmark”, Odense, Denmark", and "Gothenburg, Sweden".

Then, the Overpass API was used to query the areaID for each city by the relevant tags, which consist of a key and a value and are the semantic data of OSM. For example, nature and vegetation elements are identified by the key "Natural" and one of fewer 
customary values. Tags fall into the two informal categories, classifying tags such as the one listed on the OSM Wiki or describing tags that usually accommodate other customary values chosen spontaneously by OSM open contributors. For the purpose of this article, the natural, land use, and leisure tags with values that were not part of the OSM Wiki are seen as erroneous and were not considered for analysis. We chose the following three keys with their associated values as relevant to describe green infrastructure: natural—wood, tree_row, tree, scrub, heath, grassland, fell, shrub; landuse-allotments, farmland, farmyard, flowerbed, forest, meadow, orchard, vineyard, cemetery, grass, greenhouse_horticulture, plant_nursery, recreation_ground, normali_green; leisure-garden, nature_reserve, park. Spatial objects can be of three types: nodes, ways, relations. Nodes are single geospatial points, defined using latitude/longitude coordinates, ways consist of ordered sequences of nodes and relations are used for grouping objects together. Looking at urban GI, a tree is defined as a node, a tree row as a way and a nature reserve as a relation.

\subsection{Pre-Process the Data to Recreate an Indicator for Green Infrastructure}

By querying these tags for each of the 184 cities, we were able to count the number of green infrastructure elements in each city. Before understanding green infrastructure's relationship with the three sub-indices of the CCCM, the data was pre-processed following the steps laid out in Annex C: Statistical Assessment. Firstly, the count of green natural elements, green landuse elements and green leisure elements in each city were summed to create an overall metric for the count of green infrastructure for each city. Then, the data was normalized by population by dividing the count of green infrastructure per capita. The data possessed a high degree of outliers on the lower tail as demonstrated by the skewness of 3.95 and the kurtosis of 19.33; therefore, a windorization on $96 \%$ of the data was applied to reduce the data down to a skewness of 1.45 and a kurtosis of 1.13 below thresholds recommended by the Annex $\mathrm{C}$ of 2 and 3.5, respectively. Finally, the data was normalized on a $0-100$ scale using the min-max method, whereby the minimum and maximum of the green infrastructure metric serve as the lower and upper bound of the normalized data, allowing us to compare the data on a common scale. This allowed us to create a final D4.1 Green Infrastructure dimension for the 184 cities where data was available.

\section{Results}

Once a final D4.1 Green Infrastructure dimension was created, a Pearson correlation of the dimension was run against all the other sub-indices and dimensions of the CCCM. We found that there was a moderately positive correlation of 0.31 with the C1 Cultural Vibrancy sub-index, no correlation of 0.04 with the C2 Creative Economy, and a weak positive correlation of 0.15 with the C3 Enabling Environment sub-index. When running the correlation against the dimensions of each sub-index, the dimensions with the strongest correlation were 0.32 with D1.1 Cultural Venues and Facilities, 0.21 with D1.2 Cultural Participation and Attractiveness, 0.22 with D3.1 Human Capital and Education and 0.18 with D3.4 Quality of Governance. These results can be found in Table 1 alongside their statistical significance scores based on $p$-value.

The results vary when the analysis is broken down by city type and size. The correlation of D4.1 Green Infrastructure to C1 Cultural Vibrancy is stronger at 0.40 for European Capital of Culture cities, whereas the correlation of D4.1 Green Infrastructure to the C3 Enabling Environment is weaker for European Capitals of Culture but stronger for UNESCO Creative cities and Festival cities. In terms of city size, when looking at Table 2 the correlation of D4.1 Green Infrastructure to C1 Cultural Vibrancy is stronger at 0.38 for L Cities and 0.34 for S-M Cities compared to bigger cities. Furthermore, the correlation of D4.1 Green Infrastructure to C3 Enabling Environment is stronger at 0.29 for XXL cities and 0.28 for S-M cities. These trends can be seen in Figures 1 and 2 below. The interpretation of these results will be discussed in Section 4 . 
Table 1. Relationship of Green Infrastructure to sub-indices and dimensions by city type.

\begin{tabular}{|c|c|c|c|c|}
\hline & \multicolumn{4}{|c|}{ D4.1 Green Infrastructure } \\
\hline & All Cities & European Capital of Culture & UNESCO Creative City & Festival City \\
\hline & $\mathrm{n}=184$ & $\mathrm{n}=95$ & $\mathrm{n}=57$ & $\mathrm{n}=32$ \\
\hline C3 Index & $0.21^{* * *}$ & 0.22 & 0.08 & 0.27 \\
\hline 1. Cultural Vibrancy & $0.31^{* * *}$ & 0.40 & 0.06 & 0.21 \\
\hline 2. Creative Economy & 0.04 & 0.01 & -0.08 & 0.18 \\
\hline 3. Enabling Environment & $0.15^{* *}$ & 0.10 & 0.28 & 0.26 \\
\hline D1.1 Cultural Venues and Facilities & $0.32 * * *$ & 0.44 & -0.01 & 0.14 \\
\hline D1.2 Cultural Participation and Attractiveness & $0.21^{* * *}$ & 0.24 & 0.11 & 0.24 \\
\hline D2.1 Creative and Knowledge-based Jobs & $0.14^{* *}$ & 0.13 & -0.13 & 0.30 \\
\hline D2.2 Intellectual Property and Innovation & $0.12 *$ & 0.15 & 0.19 & 0.09 \\
\hline D2.3 New Jobs in Creative Sectors & -0.11 & -0.17 & -0.09 & -0.02 \\
\hline D3.1 Human Capital and Education & $0.22 * *$ & 0.17 & 0.27 & 0.37 \\
\hline D3.2 Openness, Tolerance and Trust & 0.02 & -0.03 & 0.18 & 0.06 \\
\hline D3.3 Local and International Connections & 0.02 & 0.04 & -0.03 & 0.05 \\
\hline D3.4 Quality of Governance & $0.18^{* *}$ & 0.18 & 0.31 & 0.23 \\
\hline
\end{tabular}

Statistical significance: ${ }^{* * *} 99 \%,{ }^{* *} 95 \%, * 90 \%$.

Table 2. Relationship of Green Infrastructure to sub-indices and dimensions by city population size.

\begin{tabular}{llllll}
\hline & D4.1 Green Infrastructure & & & \\
\hline & All Cities & XXL Cities & XL Cities & L Cities & S-M Cities \\
\hline & $\mathbf{n}=\mathbf{1 8 4}$ & $\mathbf{n = 2 0}$ & $\mathbf{n = 3 9}$ & $\mathbf{n = 4 1}$ & $\mathbf{n = 8 4}$ \\
\hline C3 Index & $0.21^{* * *}$ & 0.19 & 0.07 & 0.23 & 0.36 \\
1. Cultural Vibrancy & $0.31^{* * *}$ & 0.30 & 0.01 & 0.38 & 0.34 \\
2. Creative Economy & 0.04 & 0.00 & 0.05 & 0.06 & 0.22 \\
3. Enabling Environment & $0.15^{* *}$ & 0.29 & 0.16 & -0.02 & 0.28 \\
\hline D1.1 Cultural Venues and Facilities & $0.32^{* * *}$ & 0.16 & 0.04 & 0.42 & 0.33 \\
D1.2 Cultural Participation and Attractiveness & $0.21^{* * *}$ & 0.39 & 0.00 & 0.29 & 0.24 \\
\hline D2.1 Creative and Knowledge-based Jobs & $0.14^{* *}$ & -0.03 & -0.14 & 0.24 & 0.33 \\
D2.2 Intellectual Property and Innovation & $0.12^{*}$ & 0.11 & 0.00 & 0.23 & 0.20 \\
D2.3 New Jobs in Creative Sectors & -0.11 & -0.02 & 0.19 & -0.26 & -0.09 \\
\hline D3.1 Human Capital and Education & $0.22^{* *}$ & 0.10 & 0.36 & 0.20 & 0.31 \\
D3.2 Openness, Tolerance and Trust & 0.02 & 0.26 & 0.02 & -0.19 & 0.09 \\
D3.3 Local and International Connections & 0.02 & 0.20 & -0.29 & 0.00 & 0.19 \\
D3.4 Quality of Governance & $0.18^{* *}$ & 0.46 & 0.06 & -0.01 & 0.28 \\
\hline
\end{tabular}



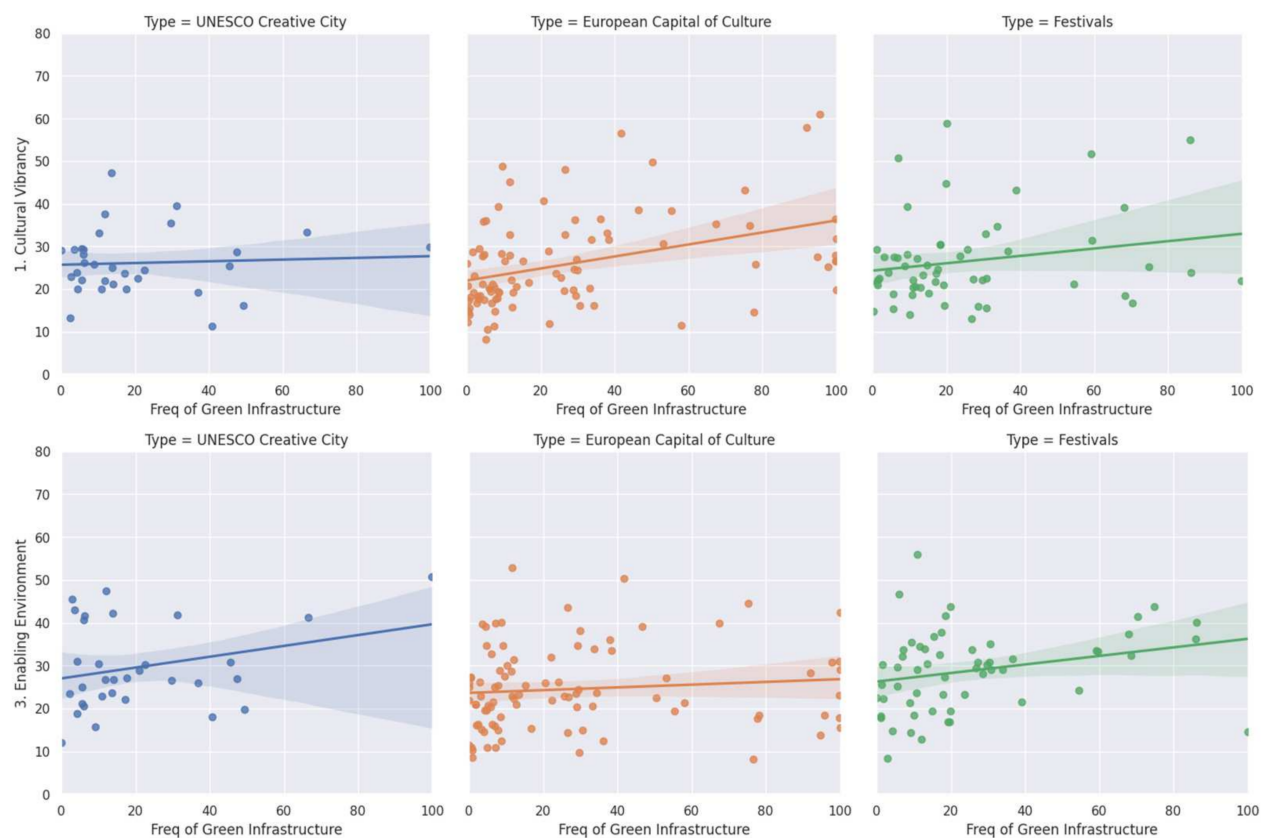

Figure 1. Relationship of Green Infrastructure to Cultural Vibrancy and Enabling Environment.
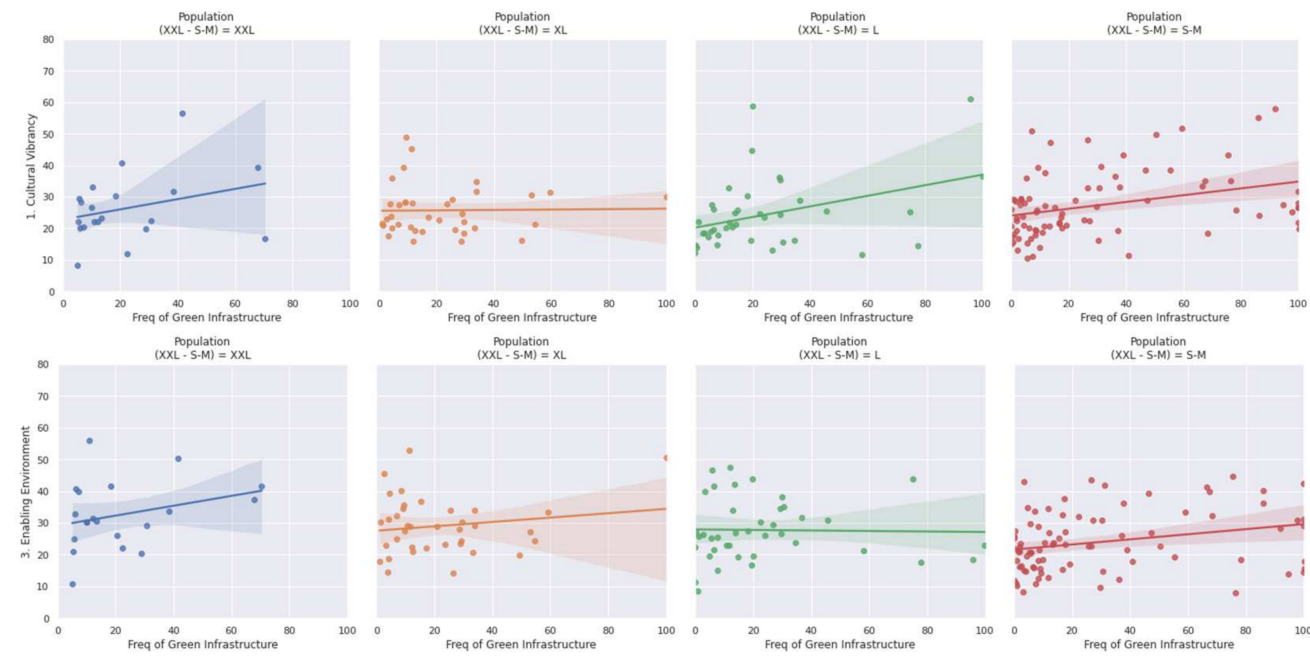

Figure 2. Relationship of Green Infrastructure to Cultural Vibrancy and Enabling Environment.

\section{Discussion}

Given that our results show that there is a moderately positive relationship between green infrastructure and cultural vibrancy and the enabling environment of European cities, we believe there is scope for the conceptual framework of the CCCM to expand and include a new Urban Nature sub-index $(\mathrm{C} 4)$ that not only encompasses a green infrastructure dimension (D4.1) but also blue infrastructure (D4.2) and other natural landforms of a city (D4.3) to create a cultural, creative and sustainable cities monitor of sorts. Even though the correlations between the D4.1 green infrastructure dimension and the C1 Cultural Vibrancy sub-index is not as strong as some other dimensions, there is enough of a signal, especially after the pandemic, for it to be included in 2021 alongside the data. If cities were to start collecting and monitoring urban nature data from now on, it will allow them to compare how urban nature and sub-indices of the CCCM are related and whether they converge or diverge from each other in the future.

Following the work from the European Commission "Evaluating the impact of Naturebased solutions" [42] and the identification of 12 areas where the creation and implementation of nature-based solutions would help to improve the climate resiliency and liveability 
of cities, we are proposing that the three dimensions are constructed from the following specific indicators:

Green Infrastructure (D4.1) would be made of the following counts per capita:

- green spaces (including urban parks and gardens, heritage parks, botanical gardens, community gardens, cemeteries, schoolyards and sports fields, meadows, green strips)

- trees and shrubs (including forests, orchards, vineyards, hedges, shrubs and green fences, street trees)

- green built environment (including green rooves, green walls and façades, green allies, temporary small-scale interventions such as green parklets or green furniture)

Blue Infrastructure (D4.2) would be made of the following counts per capita:

- $\quad$ blue spaces (including mangroves, waterbodies, waterways, rivers)

- blue built environment (including rain gardens, wet swales, infiltration basins, vegetated filter strip)

Natural Landforms and Elements (D4.3) would be made of the following per capita:

- $\quad$ wildlife (including insect hotels, apiaries, nest boxes, stopover habitat)

- climate (including peak temperature events, floods events, water quality, air quality, pollen concentration)

- $\quad$ users experience (quality of nature spaces, distance to natural spaces)

Including these indicators into the CCCM will ensure that they can be cross-referenced with the suggestions made in [42] to track the sustainability of cities; moreover, they may be related to the cultural participation, creative economy or enabling environment of cities of the CCCM. The 4.1 Green Infrastructure dimension includes urban nature and green open spaces that would allow for cultural, social, and economic activities to take place. For instance, parks and gardens may act as stages for cultural events such as art exhibitions, orchards, and vineyards as places of culinary attraction but also as places of employment. The 4.2 Blue Infrastructure dimension is similar to D4.1 but with an emphasis on urban blue spaces. Waterbodies may similarly act as spaces where cultural activities can thrive. This is illustrated, for example, by the "ImFluss Festival", which takes place on a floating stage on the Rhine River in Basel.

The 4.3 Natural Landforms and Elements dimension will allow cities to track the biodiversity, climate resilience and the accessibility of nature. For example, the wildlife indicator might include insect hostels, apiaries or nest boxes that will help benchmark the wildlife diversity in a city over time. Secondly, the climate indicator would allow cities to monitor extreme weather events and thus better understand how this impacts their cultural, social, and economic activities. Floods, extreme temperature events, high air pollution or pollen concentration are all events that tend to impede the liveability of cities for both citizens and tourism. The greater the frequency of extreme weather, the lower the score of this indicator would be. Finally, a user experience indicator would measure the average walking distance to open and green spaces reflecting the availability for cultural and social activities to happen.

The indicators of these dimensions are a starting point to include an Urban Nature sub-index in the CCCM. As documented by the EU [40] and the work of the literature on indices to evaluate nature-based solutions, there is scope to introduce other tangible indicators and review the proposed dimensions. As we explain below, the inclusion of an Urban Nature sub-index (C4) in the CCCM is heightened after the COVID-19 pandemic and in light of the EU Green Deal. The CCCM certainly has an interest in promoting sustainable tourism. The first edition of the CCCM was launched in 2018 during the European Year of Cultural Heritage with the aim to "advance reflections on the contribution of sustainable cultural tourism to urban and regional development" and to explore "how to balance the sustainability of cultural heritage with the benefits of tourism, not just in economic terms but also for the well-being of local communities". Moreover, it is noted that the EU Work Plan for Culture 2019-2022 and New European Agenda for Culture pay special attention to the role of culture at the local level; "a city cannot thrive without a lively 
cultural offering and healthy creative sectors. Flourishing local culture(s) and creativity improve citizen's quality of life, strengthen social cohesion, reinforce cognitive and relation skills, and enhance business competitiveness".

However, even though green infrastructure has been demonstrated to achieve some of these goals, it has unfortunately been overlooked by the CCCM thus far. Why consider an Urban Nature sub-index for European Cities as part of the CCCM now? The COVID-19 pandemic has underpinned the importance of cultural and societal benefits provided by urban green spaces. Not only this but several major green policy initiatives have also been launched in recent times. On 11 December 2019, the European Green Deal was first presented. Through the Green Deal, the EU aims to plant 3 billion trees and restore $25,000 \mathrm{~km}$ of EU rivers to a free-flowing state by 2030, as well as improving a whole variety of sustainable biodiversity, farming, industrial and construction methods. Adding an urban nature sub index into the monitor would give cities incentives to improve and implement more urban greening that will help them to address the goals set by the EU green deal whilst also attempting to stimulating culture in their own cities.

Other policy goals and government initiatives, especially looking at the health of urban environments, have flourished over the past years. At a global level, the Sustainable Development Goal (SDG11) of the United Nations' 2030 Agenda encourages cities to become more resilient, safer, and more sustainable, advocating for actions such as better access to open public spaces and the improvement in air quality. At the European level, the CLEVER Cities project aims to develop novel urban nature-based solutions (NBS) to help cities become more sustainable and more socially inclusive. The CLEVER Cities project regroups European and global cities and gives them a platform to exchange, collaborate and learn the best practices for greening cities and taking NBS in urban planning worldwide. The project highlights the need for cities to better understand their natural environment and some of the practical solutions to make them more nature friendly and more inclusive.

In parallel to these initiatives, at the municipality level, cities have begun to realize the role they play in occurrence of the "ecological deficit" [44]. London, Paris, and Barcelona are only a few examples of cities demonstrating the changes towards the recognition of nature, not only as aesthetic objects but also as valuable assets. The London mayor set out a $£ 12$ million Greener City Fund to support "green" activities such as community tree planting, new woodland creation, green infrastructure development and green space grants. Similarly, in the eve of the 2024 Summer Olympic Games, Paris is embracing environmental stewardship. The ambitious transformation of the Champs-Elysees into an "extraordinary garden", the rearrangement of the Jardin du Trocadero and the Champ de Mars, overhanging the Eiffel Tower, into green belts or the renovation of the Tour Montparnasse into a garden tower with gravel parks, grey rooves, and boulevards forming a giant garden. Finally, the Barcelona Green Infrastructure and Biodiversity Plan (2020) and Trees for life Master Plan (2017-2037) exemplifies the philosophy of many cities today who are championing greater green infrastructure to offer social and environmental benefits to their citizens, increasing their health and wellbeing while preserving cities' natural heritage and making them stronger to tackle future challenges.

These initiatives illustrate the two steps that Balaban [44] argues to be necessary for a green economy transition of cities and urban areas: "the greening of city-based economic processes and the greening of the production and use of urban space itself". Considering a greater emphasis on the availability and health of nature in cities, it makes sense to consider the addition of an Urban Nature index to the CCCM. Even though the demand for green spaces and nature did increase as a result of the pandemic, and may abate when economies and societies start to open back up, an Urban Nature sub-index will broaden the goal of The CCCM and not only allow to assess the level of culture and creativity in cities but also the level of nature ex-ante and ex-post the pandemic, consequently providing a better understanding for policymakers about actions and strategies to implement to tackle societal and cultural challenges in the future. 
Our research has solely relied on OSM data to count the number of green infrastructure elements of a city. OSM can also be used to count the number of blue infrastructure and landform elements in a city to create an Urban Nature sub-index. As a collective, openly accessible and free platform, OpenStreetMap has been described as "one of the most successful examples of volunteered geographic information, contributing to greater information on the map of the world" [45]. This has led to several studies researching the credibility of volunteer content. Mashhadi et al. [45] took a step further, exploring not only the positional and thematic accuracy, but also the completeness of OSM data. Focusing their study on London, they concluded that the OSM content was high in positional and thematic accuracy. However, their study shed light on the high variability in the completeness of the data between different areas of the city. This discrepancy has also been highlighted by Arsanjani et al. [46], Feltynowski et al. [47] and Le Texier et al. [48]. Their study shows that the degree of completeness and the quantity of contributions for urban green spaces vary between cities, with a tendency of greater data completeness in city centres and lower data completeness on the city outskirts. A more recent study by Ludwig et al. [49] summarizes the challenges encountered by researchers of urban green spaces such as the lack of consensus on the definition of "urban green space", the unequal sensitivity of data on private and small green spaces, and the differences in land cover indicators between municipal, national, and other geographic information systems datasets.

To improve the count of green infrastructure elements for the cities of the CCCM, future research could look to combine multiple datasets to increase completeness. For instance, Taylor et al. [50] used Google Earth to measure the quality of urban green spaces. Similarly, Ludwig et al. [49] showed that combining OSM data with Sentinel-2 satellite imagery improves assessment of urban green spaces.

\section{Conclusions}

By collecting data from OpenStreetMap, we were able to count the amount of green infrastructure in 184 European cities and correlated these results with the performance indicators of the CCCM. Our research found that there is some positive relationship between green infrastructure and the cultural vibrancy and the enabling environment of European cities. We suggest that the CCCM includes an Urban Nature sub-index in the future that encompasses not only a green infrastructure dimension but also a blue infrastructure dimension and other natural landforms of a city. This suggestion is particularly heightened following the COVID-19, where green infrastructure has seen a surge in utility as a facilitator of social interaction, sustainable tourism, and green growth; moreover, policy initiatives such as the EU Green deal, UN Sustainable Development Goals and various city-wide initiatives have advanced the importance of greening for bringing sustainable as well as societal benefits. An Urban Nature indicator as part of the CCCM will allow policymakers to advocate and lobby cities to take more steps to include sustainability and green growth in their urban environments. In order to obtain more completeness of urban nature data, future research may consider combining OpenStreetMap data with satellite imagery and machine learning techniques to understand nature coverage in cities. Furthermore, IoT sensors and devices could be installed in cities to measure real-time fluctuations in nature coverage, which may lead to more accurate spatial regressions and agent-based models to understand the benefits of urban nature at a much deeper level.

Author Contributions: Conceptualization, V.K. and A.V.; Methodology, V.K. and A.V.; Formal Analysis V.K. and A.V.; Writing V.K. and A.V.; Funding acquisition, V.K. Both authors have read and agreed to the published version of the manuscript.

Funding: This research received no external funding.

Data Availability Statement: Data from the Cultural and Creative Cities Monitor and OpenStreetMap were extremely helpful for this analysis. 
Acknowledgments: We would like to thank Valentina Montalto for her continued support and the Joint Research Centre at the European Commission for their great work producing and maintaining the Cultural and Creative Cities Monitor for researchers like ourselves to use for analysis.

Conflicts of Interest: The authors declare no conflict of interest.

\section{References}

1. Venter, Z.S.; Barton, D.N.; Gundersen, V.; Figari, H.; Nowell, M. Urban nature in a time of crisis: Recreational use of green space increases during the COVID-19 outbreak in Oslo, Norway. Environ. Res. Lett. 2020, 15, 104075. [CrossRef]

2. Day, B.H. The Value of Greenspace Under Pandemic Lockdown. Environ. Resour. Econ. 2020, 76, 1161-1185. [CrossRef] [PubMed]

3. Kleinschroth, F.; Kowarik, I. COVID-19 crisis demonstrates the urgent need for urban greenspaces. Front. Ecol. Environ. 2020, 18, 318-319. [CrossRef] [PubMed]

4. Ugolini, F.; Massetti, L.; Calaza-Martínez, P.; Cariñanos, P.; Dobbs, C.; Ostoić, S.K.; Marin, A.M.; Pearlmutter, D.; Saaroni, H.; Šaulienè, I.; et al. Effects of the COVID-19 pandemic on the use and perceptions of urban green space: An international exploratory study. Urban For. Urban Green. 2020, 56, 126888. [CrossRef]

5. Hanzl, M. Urban forms and green infrastructure-The implications for public health during the COVID-19 pandemic. Cities Health 2020, 1-5. [CrossRef]

6. Herman, K.; Drozda, Ł. Green Infrastructure in the Time of Social Distancing: Urban Policy and the Tactical Pandemic Urbanism. Sustainability 2021, 13, 1632. [CrossRef]

7. Lutyens, D. Five Stunning OUTDOOR Spaces for All. BBC 2020. Available online: https://www.bbc.com/culture/article/202006 02-five-stunning-outdoor-spaces-for-all (accessed on 26 May 2021).

8. Honey-Rosés, J.; Anguelovski, I.; Chireh, V.K.; Daher, C.; van den Bosch, C.K.; Litt, J.S.; Mawani, V.; McCall, M.K.; Orellana, A.; Oscilowicz, E.; et al. The impact of COVID-19 on public space: An early review of the emerging questions-Design, perceptions and inequities. Cities Health 2020, 1-17. [CrossRef]

9. Naumann, S. Design, Implementation and Cost Elements of Green Infrastructure Projects; European Comission: Brussels, Belgium, 2011; p. 142.

10. Gilbert, O.L. The Ecology of Urban Habitats; Springer: Dordrecht, The Netherlands, 1991; ISBN 978-0-412-45500-1.

11. Mortberg, U. Red-Listed Forest Bird Species in an Urban Environment-Assessment of Green Space Corridors-ScienceDirect. Available online: https:/ / www-sciencedirect-com.libproxy.ucl.ac.uk/science/article/pii/S0169204600000906?via\%3Dihub (accessed on 23 May 2021).

12. Payne, S.; Barker, A. Implementing green infrastructure through residential development in the UK. In Handbook on Green Infrastructure; Edward Elgar Publishing: Cheltenham, UK, 2015; pp. 375-394.

13. Mentens, J.; Raes, D.; Hermy, M. Green roofs as a tool for solving the rainwater runoff problem in the urbanized 21st century? Landsc. Urban Plan. 2006, 77, 217-226. [CrossRef]

14. Armson, D.; Stringer, P.; Ennos, A.R. The effect of street trees and amenity grass on urban surface water runoff in Manchester, UK. Urban For. Urban Green. 2013, 12, 282-286. [CrossRef]

15. Frumkin, H. Healthy places: Exploring the evidence. Am. J. Public Health 2003, 93, 1451-1456. [CrossRef]

16. Hunter, R.F.; Christian, H.; Veitch, J.; Astell-Burt, T.; Hipp, J.A.; Schipperijn, J. The impact of interventions to promote physical activity in urban green space: A systematic review and recommendations for future research. Soc. Sci. Med. 2015, 124, 246-256. [CrossRef]

17. Ward Thompson, C.; Roe, J.; Aspinall, P.; Mitchell, R.; Clow, A.; Miller, D. More green space is linked to less stress in deprived communities: Evidence from salivary cortisol patterns. Landsc. Urban Plan. 2012, 105, 221-229. [CrossRef]

18. Coley, R.L.; Sullivan, W.C.; Kuo, F.E. Where Does Community Grow?: The Social Context Created by Nature in Urban Public Housing. Environ. Behav. 1997, 29, 468-494. [CrossRef]

19. Kuo, F.E.; Sullivan, W.C.; Coley, R.L.; Brunson, L. Fertile Ground for Community: Inner-City Neighborhood Common Spaces. Am. J. Community Psychol. 1998, 26, 823-851. [CrossRef]

20. Kweon, B.-S.; Sullivan, W.C.; Wiley, A.R. Green Common Spaces and the Social Integration of Inner-City Older Adults. Environ. Behav. 1998, 30, 832-858. [CrossRef]

21. de Vries, S.; van Dillen, S.M.E.; Groenewegen, P.P.; Spreeuwenberg, P. Streetscape greenery and health: Stress, social cohesion and physical activity as mediators. Soc. Sci. Med. 2013, 94, 26-33. [CrossRef]

22. Sugiyama, T.; Leslie, E.; Giles-Corti, B.; Owen, N. Associations of neighbourhood greenness with physical and mental health: Do walking, social coherence and local social interaction explain the relationships? J. Epidemiol. Community Health 2008, 62, e9. [CrossRef]

23. Dinnie, E.; Brown, K.M.; Morris, S. Community, cooperation and conflict: Negotiating the social well-being benefits of urban greenspace experiences. Landsc. Urban Plan. 2013, 118, 103-111. [CrossRef]

24. Sallis, J.F.; Conway, T.L.; Cain, K.L.; Carlson, J.A.; Frank, L.D.; Kerr, J.; Glanz, K.; Chapman, J.E.; Saelens, B.E. Neighborhood built environment and socioeconomic status in relation to physical activity, sedentary behavior, and weight status of adolescents. Prev. Med. 2018, 110, 47-54. [CrossRef]

25. Kazmierczak, B.I.; Hendrixson, D.R. Spatial and numerical regulation of flagellar biosynthesis in polarly flagellated bacteria. Mol. Microbiol. 2013, 88, 655-663. [CrossRef] 
26. Mowen, A.J.; Rung, A.L. Park-based social capital: Are there variations across visitors with different socio-demographic characteristics and behaviours? Leisure/Loisir 2016, 40, 297-324. [CrossRef]

27. Shanahan, D.F.; Bush, R.; Gaston, K.J.; Lin, B.B.; Dean, J.; Barber, E.; Fuller, R.A. Health Benefits from Nature Experiences Depend on Dose. Sci. Rep. 2016, 6, 28551. [CrossRef]

28. Holtan, M.T.; Dieterlen, S.L.; Sullivan, W.C. Social Life Under Cover: Tree Canopy and Social Capital in Baltimore, Maryland. Environ. Behav. 2015, 47, 502-525. [CrossRef]

29. Ulmer, J.M.; Wolf, K.L.; Backman, D.R.; Tretheway, R.L.; Blain, C.J.; O’Neil-Dunne, J.P.; Frank, L.D. Multiple health benefits of urban tree canopy: The mounting evidence for a green prescription. Health Place 2016, 42, 54-62. [CrossRef]

30. Jibril, J.D.; Elfartas, H.O. Contextual Predictors of Urban Park Utilisation among Malaysian Ethnic Groups. Available online: https: / tuengr.com/V09/197M.pdf (accessed on 24 May 2021).

31. Sullivan, W.C.; Kuo, F.E.; Depooter, S.F. The Fruit of Urban Nature: Vital Neighborhood Spaces. Environ. Behav. 2004, 36, 678-700. [CrossRef]

32. Cohen, D.A.; Inagami, S.; Finch, B. The built environment and collective efficacy. Health Place 2008, 14, 198-208. [CrossRef]

33. Cattell, V.; Dines, N.; Gesler, W.; Curtis, S. Mingling, observing, and lingering: Everyday public spaces and their implications for well-being and social relations. Health Place 2008, 14, 544-561. [CrossRef]

34. Hale, R.; Calosi, P.; McNeill, L.; Mieszkowska, N.; Widdicombe, S. Predicted levels of future ocean acidification and temperature rise could alter community structure and biodiversity in marine benthic communities. Oikos 2011, 120, 661-674. [CrossRef]

35. Mangadu, T.; Kelly, M.; Orezzoli, M.C.E.; Gallegos, R.; Matharasi, P. Best practices for community gardening in a US-Mexico border community. Health Promot. Int. 2017, 32, 1001-1014. [CrossRef] [PubMed]

36. Noone, S.; Jenkins, N. Digging for Dementia: Exploring the experience of community gardening from the perspectives of people with dementia. Aging Ment. Health 2018, 22, 881-888. [CrossRef]

37. Kingsley, J.Y.; Townsend, M.; Henderson-Wilson, C. Cultivating health and wellbeing: Members' perceptions of the health benefits of a Port Melbourne community garden. Leis. Stud. 2009, 28, 207-219. [CrossRef]

38. Huang, S.-C.L. A study of outdoor interactional spaces in high-rise housing. Landsc. Urban Plan. 2006, 78, 193-204. [CrossRef]

39. Gobster, P.H. Urban parks as green walls or green magnets? Interracial relations in neighborhood boundary parks. Landsc. Urban Plan. 1998, 41, 43-55. [CrossRef]

40. Montalto, V.; Tacao Moura, C.J.; Alberti, V.; Panella, F.; Saisana, M. The Cultural and Creative Cities Monitor: 2019 Edition; EUR 29797 EN; Publications Office of the European Union: Luxembourg, 2019; ISBN 978-92-76-08807-3.

41. Bauduceau, N.; Berry, P.; Cecchi, C.; Elmqvist, T.; Fernandez, M.; Hartig, T.; Krull, W.; Mayerhofer, E.N.S.; Noring, L.; RaskinDelisle, K.; et al. Towards an EU Research and Innovation Policy Agenda for Nature-Based Solutions E Re-Naturing Cities: Final Report of the Horizon 2020 Expert Group on 'Nature-Based Solutions and Re-Naturing Cities'; Publications Office of the European Union: Brussels, Belgium, 2015. [CrossRef]

42. European Commission Evaluating the Impact of Nature-Based Solutions: A Handbook for Practitioners. Available online: https:/ / ec.europa.eu/info/news/evaluating-impact-nature-based-solutions-handbook-practitioners-2021-may-06_en (accessed on 24 May 2021).

43. Deal, G. Communication from the Commission to the European Parliament, the European Council, the Council, the European Economic and Social Committee and the Committee of the Regions. 2018. Available online: https: / /op.europa.eu/en/publicationdetail/- / publication/b828d165-1c22-11ea-8c1f-01aa75ed71a1/language-en (accessed on 28 May 2021).

44. Balaban, O. Chapter 5-Smart cities as drivers of a green economy. In Handbook of Green Economics; Acar, S., Yeldan, E., Eds.; Academic Press: Cambridge, MA, USA, 2019; pp. 69-92. ISBN 978-0-12-816635-2.

45. Mashhadi, A.; Quattrone, G.; Capra, L. The Impact of Society on Volunteered Geographic Information: The Case of OpenStreetMap. In OpenStreetMap in GIScience; Jokar Arsanjani, J., Zipf, A., Mooney, P., Helbich, M., Eds.; Lecture Notes in Geoinformation and Cartography; Springer International Publishing: Cham, Switzerland, 2015; pp. 125-141. ISBN 978-3-319-14279-1.

46. Jokar Arsanjani, J.; Mooney, P.; Zipf, A.; Schauss, A. Quality Assessment of the Contributed Land Use Information from OpenStreetMap Versus Authoritative Datasets. In OpenStreetMap in GIScience: Experiences, Research, and Applications; Jokar Arsanjani, J., Zipf, A., Mooney, P., Helbich, M., Eds.; Lecture Notes in Geoinformation and Cartography; Springer International Publishing: Cham, Switzerland, 2015; pp. 37-58. ISBN 978-3-319-14280-7.

47. Feltynowski, M.; Kronenberg, J.; Bergier, T.; Kabisch, N.; Łaszkiewicz, E.; Strohbach, M.W. Challenges of urban green space management in the face of using inadequate data. Urban For. Urban Green. 2018, 31, 56-66. [CrossRef]

48. Le Texier, M.; Schiel, K.; Caruso, G. The provision of urban green space and its accessibility: Spatial data effects in Brussels. PLoS ONE 2018, 13, e0204684. [CrossRef]

49. Ludwig, C.; Hecht, R.; Lautenbach, S.; Schorcht, M.; Zipf, A. Mapping Public Urban Green Spaces Based on OpenStreetMap and Sentinel-2 Imagery Using Belief Functions. ISPRS Int. J. Geo Inf. 2021, 10, 251. [CrossRef]

50. Taylor, B.T.; Fernando, P.; Bauman, A.E.; Williamson, A.; Craig, J.C.; Redman, S. Measuring the quality of public open space using Google Earth. Am. J. Prev. Med. 2011, 40, 105-112. [CrossRef] 